\begin{tabular}{|c|c|c|}
\hline $\begin{array}{l}\text { PKS } \\
\text { PUBLIC } \\
\text { KNOWLEDGE } \\
\text { PROJECT }\end{array}$ & $\begin{array}{c}\text { REVISTA DE GEOGRAFIA } \\
\text { (RECIFE) } \\
\text { http://ww.revista.ufpe.br/revistageografia }\end{array}$ & 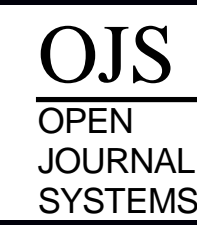 \\
\hline
\end{tabular}

\title{
A REDE DE PODER DO TRANSPORTE COLETIVO DE MARINGÁ - PR
}

\author{
Rodrigo Vilas Boas de Souza ${ }^{1}$, Márcia da Silva ${ }^{2}$
}

\begin{abstract}
${ }^{1}$ Mestre em Geografia pela Universidade Estadual de Maringá. E-mail: rodrigo.vilasboas@outlook.com ${ }^{2}$ Docente no Programa de Pós-Graduação em Geografia da Universidade Estadual do Centro-Oeste (Unicentro), Campus Cedeteg. E-mail: marcia.silvams@gmail.com
\end{abstract}

Artigo recebido em 11/04/2017 e aceito em 21/10/2017

\begin{abstract}
RESUMO
O presente artigo apresenta os resultados de uma dissertação de mestrado que pesquisou como os grupos político-econômicos em Maringá se relacionam em rede quando o contexto é o transporte coletivo, com a finalidade de compreender quais são os interesses desses grupos na elaboração de políticas públicas para o serviço. Assim, utilizamos a metodologia de redes sociais de Alejandro e Norman (2005), a qual permitiu analisar a rede em três elementos: centralidade, intermediação e proximidade. Como resultado, constatou-se que alguns grupos detêm o poder de controlar outros atores/grupos para fazer permanecer seus interesses, como a Associação Comercial e Empresarial de Maringá (ACIM) conjunta ao Conselho de Desenvolvimento Econômico de Maringá (CODEM), a empresa Transporte Coletivo Cidade Canção (TCCC), a Prefeitura Municipal de Maringá e a Câmara Municipal de Maringá. Por isso, a rede é denominada como rede de poder, pois esses grupos político-econômicos são os que direcionam as políticas públicas em benefício próprio.
\end{abstract}

Palavras-chave: Transporte coletivo; Rede de poder; Políticas públicas.

\section{THE NETWORK OF POWER PUBLIC TRANSPORTATION OF MARINGÁ - PR}

\begin{abstract}
The article presents the result of a paper researched about how groups political-economic, in Maringá, they if relate - in network - when context é public transportation, with purpose to understand which are the interests this groups in public policy. Therefore, we used methodology network social of Alejandro and Norman (2005), which analyze the network three elements: centrality, betweenness and closenness. How result, it was verified somebody groups have the power to control other groups to make to remain their interest, for example Associação Comercial e Empresarial de Maringá (ACIM) together Conselho de Desenvolvimento Econômico de Maringá (CODEM), the company Transporte Coletivo Cidade Canção (TCCC), Prefeitura Municipal de Maringá and Câmara Municipal de Maringá. Because, the network is so-called network of power, for this groups political-economic are what manipulate the public policy in self - interest.
\end{abstract}

Keywords: Public transportation; Network of power; Public policy. 


\section{INTRODUÇÃO}

As relações de indivíduos, grupos, instituições, empresas e entidades, são recorrentes na execução de serviços urbanos, principalmente para os detentores do poder, empresários, políticos, profissionais da área jurídica e etc, que sempre estão próximos uns dos outros com a intenção de manter seus interesses, criando, assim, contatos (redes), para influenciar os outros membros da sociedade,

Nesse sentido, o presente artigo, resultado de uma dissertação de mestrado, pretende apresentar como os grupos político-econômicos se relacionam na elaboração de políticas públicas quando o contexto é o transporte coletivo. O recorte espacial de análise é a cidade de Maringá no norte do Paraná (figura 1) que possui cerca de 403.063 mil habitantes (IBGE, 2016) e somente uma empresa de ônibus para atender as demandas da população.

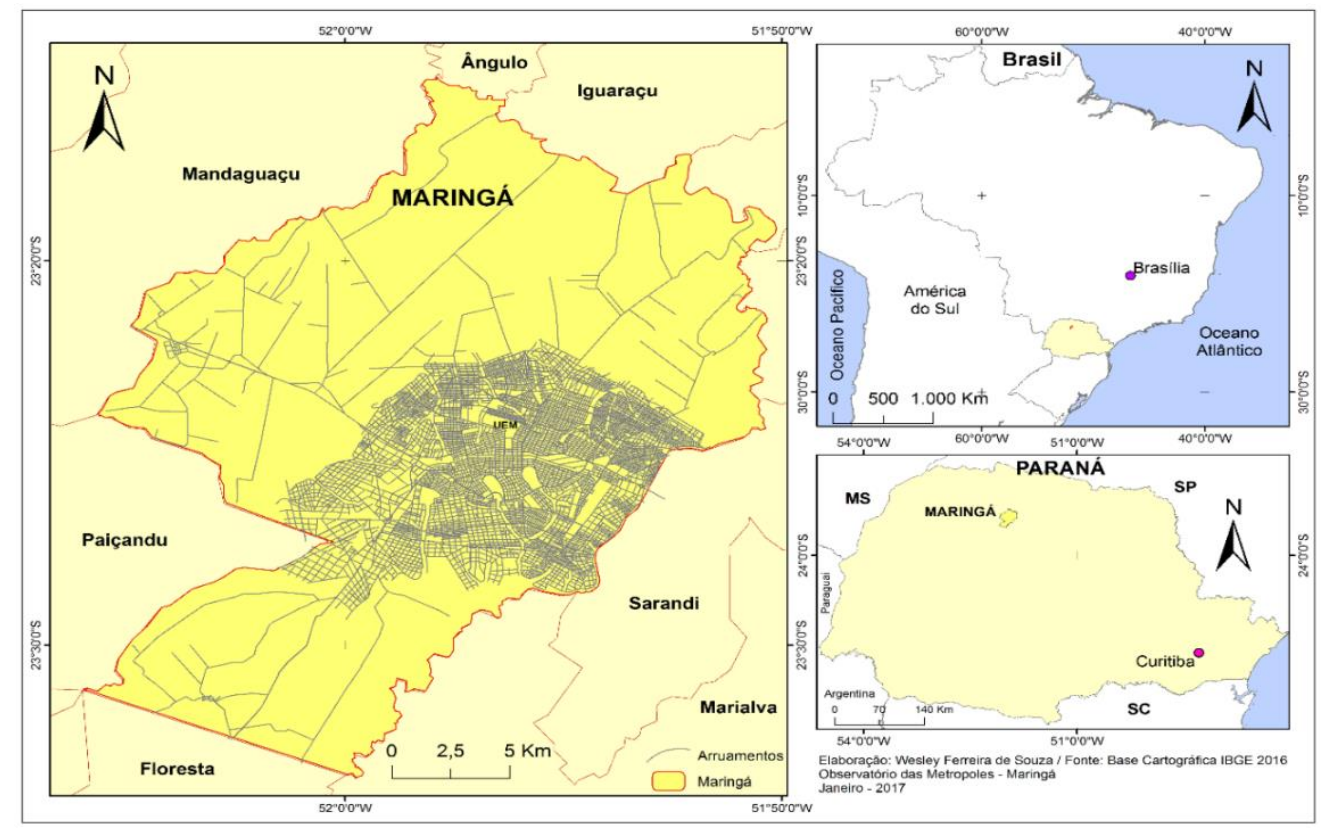

Figura 1 - Maringá: Localização do Município

Fonte: Base Cartográfica IBGE (2016)

Org.: SOUZA, W.F. (2016)

Assim, analisamos as relações dos grupos político-econômicos de Maringá por meio de redes, para entender quais são os interesses, as concessões, os conflitos e as omissões, quando o contexto é o transporte coletivo.

Para isso a pesquisa está dívida em três momentos. O primeiro aborda as questões teóricas sobre rede, com o propósito de esclarecer que entre a rede social e a rede geográfica encontra-se a rede de poder, aquela que não quer ser vista e é controlada por grupos político- 
econômicos com interesses específicos, por isso denominamos de rede de poder, como acontece no âmbito do transporte coletivo em várias cidades brasileira, sendo Maringá somente um recorte dessas práticas. Os autores que contribuíram para essas reflexões são: Corrêa (2012), Marques (1998, 2003 e 2006), Marteleto (2001), Raffestin (1993) e Santos (2002).

O segundo momento apresenta a metodologia utilizada para analisar a rede, assim, produzimos as informações no software UCINET 6.624 e NetDraw 2.160 e selecionamos três elementos de estudo: centralidade, intermediação e proximidade. Os quais foram fundamentados a partir de autores como Alejandro e Norman (2005) e Tomél e Marteleto (2006).

Por fim, a última parte da pesquisa é a análise da rede de poder do transporte coletivo de Maringá, que se configura a partir dos grupos político-econômicos. Os nomes selecionados foram pautados no Conselho Municipal de Transportes Urbanos e Mobilidade Urbana, no Conselho de Transporte Urbanos e no Relatório da Comissão Parlamentar de Inquérito (CPI) do Transporte Coletivo de Maringá. O critério para utilizar os conselhos e o relatório, é devido os mesmos serem a única sistematização formal no Município de Maringá quando as circunstâncias envolvem o transporte coletivo. Assim, visto que são compostos por muitas entidades, associações, secretarias e organizações sociais, selecionamos 25 nomes compreender as relações de poder político-econômico.

\section{ENTRE A REDE SOCIAL E A REDE GEOGRÁFICA ESTÁ A REDE DE PODER}

A proposta deste trabalho é utilizar a rede social como a origem de todas as interações entre grupos e indivíduos, sendo que é a partir dela que entendemos como os atores de uma de rede se conectam e quais são seus interesses. Enquanto a rede geográfica é a espacialização de todas essas relações sociais, o resultado de decisões políticas e econômicas no espaço.

Nesse sentido, identificamos entre a rede social e a rede geográfica a rede de poder, sendo aquela que não quer ser vista; que tem intenções homogêneas e concentradas; a qual o consenso se sobrepõe ao confronto por meio da centralidade; da intermediação de informações e; da proximidade que os grupos e indivíduos exercem dentro dessa rede. Além disso, essas ações são comandadas por grupos com poder de decisão político-econômico. Santos (2002) entende que as redes se afirmam em duas grandes matrizes. A primeira é formada pelos aspectos materiais, constituídos no território, como as redes de energia, de 
transporte, de infraestrutura etc.; enquanto que a segunda é formada pelas redes sociais e políticas, as quais são organizadas e transmitidas por meio de mensagens, pessoas e valores.

Assim, a rede social é a origem da nossa análise, pois está centrada nas relações de indivíduos e entidades inseridos em situações sociais, que possibilita a percepção de diferentes elementos sociais, por exemplo, o de verificar as interações de organizações em estrutura de lobby, as relações de amizades no interior das elites, as intermediações de interesses nas políticas urbanas, as mobilizações políticas de estudantes e entre outras possibilidades. Assimilar essas situações sociais significa permitir o detalhamento dos relacionamentos entre atores e organizações, para demonstrar as mudanças de interações no tempo (MARQUES, 1998).

Neste contexto, a estrutura geral de uma rede possibilita moldar as ações e as estratégias a partir da posição de atores/grupos que nela estão inseridos, criando alianças, confrontos, visões de mundo e preferências, além de permitir acesso aos distintos recursos de poder, como status, prestígio, dinheiro e conhecimento. Esses são atributos dos bem posicionados na rede, como um grupo/ator central em relação aos demais, os quais possuem o poder de decidir sobre temas importantes para todos, como a transição de informações entre eles para alcançar o conjunto da rede, sendo, então, características essenciais para detalhar a realidade social, sem perder de vista os padrões mais gerais da estrutura (MARQUES, 1998), pois quando a análise se faz nas políticas públicas é necessário ir além da ação do Estado para identificar os outros grupos político-econômicos que compõe uma rede em determinados assuntos.

Corroborando à reflexão, salientamos que, de acordo com Marques (2006), utilizar as redes para os estudos de políticas públicas são importantes, porque permite verificar a interdependência de atores presentes na produção de políticas públicas e as suas estratégias e influências. Isso é possível quando se define determinadas ações, o que permite a observação do contexto, no qual o desenvolvimento de uma política pública está inserido, por exemplo, a conjuntura da elaboração das políticas públicas do transporte coletivo de Maringá, restrito a alguns grupos político-econômicos como os aqui pesquisados.

Portanto, quando as políticas públicas e as redes são formadas, alguns grupos predominam mais que outros. Marques (2003) elenca três grupos que possuem posições vantajosas: os membros da classe política, os capitais envolvidos com a produção concreta de obras e de serviços contratados pelo Estado e os membros das burocracias do Estado, envolvidos direta e indiretamente com a política. Ainda dentro desses três grupos, o autor destaca outros três com o poder de decisão no contexto urbano. Os primeiros são aqueles 
ligados às atividades imobiliárias, da incorporação, dos financiamentos e da terra urbana. $\mathrm{O}$ segundo concerne aos envolvidos com a produção de infraestrutura urbana, as empreitaras, as companhias de energia e de saneamento. Já o terceiro relaciona-se aos serviços urbanos, de transporte e de limpeza urbana, tendo como único comprador o Estado, em que as ações são efetivadas por fortes relações políticas (MARQUES, 2003).

Partindo do exposto, ao pesquisarmos as políticas públicas para o transporte coletivo de Maringá, identificamos também grupos em posições privilegiadas, como os propostos por Marques (2003). Os membros da classe política, como a Prefeitura de Maringá e a Câmara Municipal de Maringá, sendo os responsáveis pela intermediação, para efetivar e legalizar as políticas públicas; os membros que participam da burocracia do Estado de forma indireta, como a Associação Comercial e Empresarial de Maringá (ACIM) conjunta com o Conselho de Desenvolvimento Econômico de Maringá (CODEM), que são grupos que não passam pelo processo eleitoral, mas estão presentes nessa rede de forma ativa, ao calcular o predomínio dos seus projetos urbanos/econômicos; e o Grupo Constantino, como proprietário da empresa Transporte Coletivo Cidade Canção (TCCC), que pelo seu poder político, influencia as decisões do poder público para benefício próprio. Desse modo, constatamos que são relações como as descritas que definem as políticas públicas para o transporte coletivo e a partir delas desenvolvem-se as redes geográficas do transporte coletivo, a qualidade dos ônibus, os terminais, os pontos de paradas, os corredores de ônibus e toda a infraestrutura para o sistema de transporte coletivo. Entretanto, isso não depende somente de um grupo, pois é uma rede que se forma em torno dos interesses que envolvem o serviço.

Corrêa (2012, p. 200) afirma que "as redes geográficas são redes sociais espacializadas", já que são construídas pelos homens no contexto das relações sociais, seja de poder ou de cooperação, por meio das alianças ou das divergências. Dito isso, a rede geográfica só é constituída quando há a intervenção do homem no espaço (CORRÊA, 2012), com base em ações que a constroem, não de forma espontânea, haja visto que são permeadas de interesses político-econômico, produzidos no tempo por grupos e atores com o poder de decisão e influência.

Para Raffestin (1993), há duas características fundamentais que os grupos consideram para dominar o espaço: a circulação como transferência de seres e bens lato sensu e a comunicação sendo a transferência de informações. O primeiro, a circulação, significa a imagem do poder, "visível pelos fluxos de homens e de bens que mobiliza, pelas infraestruturas que supõe. Nesse caso, o poder não pode evitar que seja "visto", que seja 
“controlado" (RAFFESTIN, 1993, p. 202). Dessa forma, o poder chama a atenção daquele que tem o interesse de controlá-lo e vigiá-lo, pois fornece informações, porém nem sempre ele quer se mostrar, já que, segundo o autor, o ideal do poder "é ver sem ser visto" (RAFFESTIN, 1993, p.202). Por isso, o autor afirma que a segunda característica, a comunicação, tornou-se importante na sociedade atual, porque com ela o poder pode "controlar, vigiar, interceptar, praticamente sem ser visto" (RAFFESTIN, 1993, p. 202).

Desse modo, percebe-se que a rede de poder do transporte coletivo de Maringá desenvolve-se por meio dessas bases, pois os grupos responsáveis pelos rumos das políticas públicas que detêm o poder político-econômico de decidir sobre assuntos como o aumento da tarifa, as cláusulas da licitação, a qualidade e a eficiência dos ônibus, a criação e a desativação dos conselhos municipais, a administração de recursos dos fundos municipais, tem objetivo de estar presente na rede para controlar todas essas informações e não serem identificados.

Portanto, nesta pesquisa, as redes se comunicam, para originar o que convencionamos chamar de rede de poder. A rede social é o início das relações, em que em torno de interesses comuns são estabelecidas, para, a partir dela, surgir a rede de poder, a qual preserva a intenção de omitir as informações, distanciar-se quando necessário, formar consensos, obter benefícios e controlar sem ser vista. Os resultados desses vínculos são visíveis nas redes geográficas, pois são elas a materialização de todas as relações políticoeconômicas dos grupos.

\section{PROCEDICMENTO METODOLÓGICO PARA A REPRESENTAÇÃO DA REDE DE PODER}

Para criar o sociograma da rede de poder do transporte coletivo de Maringá, tivemos como base metodológica os elementos e os indicadores de uma rede social, a qual foi gerada no programa UCINET 6.624 e o NetDraw 2.160. Para isso, os elementos que mais correspondem à análise, criados a partir da rede social, são os nós/atores, vínculos e fluxos, pois são as três características da rede que permitem determinar onde estão os atores, quais são seus vínculos e com quem se relacionam. Os nós/atores são as pessoas ou grupos que se unem com um objetivo comum, representados por figuras geométricas. Os vínculos são os laços que se criam entre dois ou mais atores, representados por linhas. Já os fluxos indicam a direção dos vínculos e correspondem às setas, em que os atores podem criar interações simultâneas ou não, por exemplo $B$ interage com $C$ e vice-versa, $C$ interage com $B$ e não o 
inverso e quando E não interage com ninguém é um nó solto dentro da rede (ALEJANDRO, NORMAN, 2005).

A figura 2 demonstra a interação de atores em uma rede. Os círculos amarelos são os atores, as linhas são os vínculos e as setas são os fluxos. Há atores que interagem entre si, outros que recebem a interação e, ainda, aqueles que não se comunicam com ninguém.

Figura 2 - Modelo de rede e possibilidades entre nós

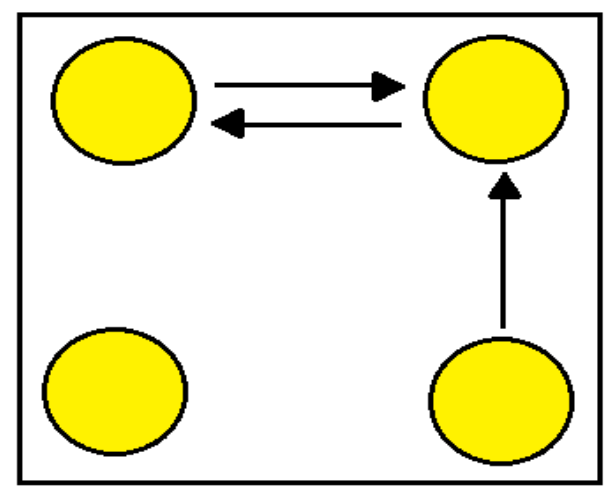

Fonte: Alejandro, Norman (2005)

Org.: SOUZA, R.V.B. (2016)

Nesse sentido, a reprodução das redes ocorre por meio de representações gráficas e matemáticas, com a finalidade de reproduzir diferentes contextos, os quais envolvem atores sociais e grupos. Na representação, os nós (pontos) são os grupos, as entidades, as organizações e os atores, enquanto as relações (linhas) são os vínculos de tipos diversos, que podem ser materiais, imateriais, de conteúdos múltiplos e de constante transformação (MARQUES, 1998). A rede social também é construída por diversos indicadores, dentre os quais utilizamos: a centralidade, a intermediação e a proximidade.

A centralidade (Centrality) significa o número no qual o ator está diretamente ligado. Isso quer dizer: divide-se em grau de saída (soma das interações que o ator tem com outros atores) e em grau de entrada (soma das interações que os outros nós tem com o ator). As interações são as relações estabelecidas entre um ator e seus pares, que não se configuram apenas como vínculo, já que pode ocorrer mais de uma interação entres os atores, dependendo o número de citações que vinculam os atores, quanto maior o número de interações maior a força do vínculo (DENEZ, 2015; ALEJANDRO, NORMAN, 2005). Assim, a "análise, mesmo sendo individualizada, já que importa os contatos diretos do mesmo, é realizada no conjunto da rede, na posição do ator em relação aos demais atores” (SILVA, 2005, p.210), ou seja, é um ator que está bem posicionado pela quantidade de informação e recursos que detêm e, por isso, tem menor dependência em relação a outros atores. Para compreender o grau de 
centralidade, consideramos o grau de entrada, aquilo que o ator recebe de informação e o torna central na rede.

Desse modo, os atores centrais em uma rede são os "que estão em posições estratégicas - em termos de informação -, são as pessoas reconhecidas na rede como importantes e sendo, por isso, mais intenso o compartilhamento de informação com elas" (TOMAÉL, MARTELETO, 2006, p.80)

O segundo indicador, a intermediação, concerne às possibilidades de um ator como meio para alcançar e intermediar a comunicação entre outros atores nos caminhos geodésicos $^{1}$. Encontra-se nas vezes que um ator aparece nos caminhos que ligam todos os pares de nós à rede, os quais podem ser chamados de atores pontes. Para um ator ter grau de intermediação é necessário ter pelo menos um grau de saída e um grau de entrada (ALEJANDRO, NORMAN, 2005; TOMAÉL, MARTELETO, 2006). Além disso, um ator pode não ter muitos contatos diretos, entretanto, pode apresentar uma importância fundamental na mediação de trocas, como será visto na rede de poder do transporte coletivo de Maringá. Isso representa, portanto, que esse ator tem o poder de controlar as informações e as possibilidades de caminhos que elas podem transitar (TOMAÉL, MARTELETO, 2006).

A proximidade, como último indicador de análise, significa a distância de um ator em relação aos outros atores da rede, baseado na distância geodésica, considerando, ainda, as distâncias diretas e indiretas, sendo que quanto menor o valor da soma das internações, mais próximo um ator está dos outros nós da rede. Desse modo, “esses atores, devido aos contatos com o mínimo de intermediários possível, têm acesso à informação mais confiável, isto porque a recebem, praticamente, da fonte" (TOMAÉL, MARTELETO, 2006, p. 84).

Entretanto, antes de construir o sociograma é necessário organizar as informações em uma matriz quadrada, a qual, para esta pesquisa, distribuímos questionários para os 25 nomes que formam a rede de poder do transporte coletivo, com a seguinte descrição:

Solicita-se a sua ajuda com o objetivo de identificar os principais grupos políticos/econômicos e as instituições que se relacionam com o transporte público coletivo de Maringá. A partir da lista com base nos nomes de políticos, instituições e empresas, quais o (a) o senhor (a) indicaria como tendo alguma relação entre a entidade que representa com as demais relacionadas abaixo? (Menos a qual o senhor (a) representa. Ao final, por gentileza, assinar o documento).

Após os resultados, inserimos as informações na matriz, organizando os nomes em linhas e colunas. Os vínculos entre os grupos e indivíduos foram registrados com o número 1, por exemplo: A disse que faz interação com B, então, na linha de A relacionamos à coluna de 
B e colocamos o número 1, sucessivamente, e os espaços vazios foram preenchidos pelo número 0 .

A escolha dos nomes para compor a lista, como exposto na introdução, surgiu de dois conselhos, o Conselho Municipal de Transportes Públicos e Mobilidade Urbana e o Conselho Municipal de Transporte Urbanos, além do Relatório da Comissão Parlamentar de Inquérito (CPI dos Transportes), que nortearam a procura dos atores mais apropriados para responder o questionário. Continuamente, selecionamos os 25 nomes que tinham alguma relação com o transporte coletivo e aplicamos os questionários entre o mês de setembro e novembro de 2016.

Desse modo, os dois conselhos selecionados servem como parâmetros para análise da rede, por serem a única referência no município organizada, formalmente, para debater o transporte coletivo, além da diferença de representantes em cada um. O primeiro, aprovado em 2002, tinha uma lista restrita com pouca participação da população e da sociedade civil. O segundo, em 2013, inseriu segmentos como movimentos sociais, conselheiros de bairros, universidades e a empresa de transporte coletivo. Entendemos, com isso, que não caberia adicionar, na análise da rede, aqueles que se distanciavam do serviço, como os taxistas, o grupo do transporte escolar, a associação dos agentes de viagens, o sindicato dos trabalhadores rodoviários e os estudantes. Portanto, o objetivo não é idealizar um possível funcionamento do conselho, mas compreender, a partir de uma lista pré-estabelecida, como os grupos político-econômico se relacionam quando o assunto é transporte coletivo.

\section{A REDE DE PODER DO TRANSPORTE COLETIVO DE MARINGÁ}

A rede de poder do transporte coletivo de Maringá pode ser interpretada sob diferentes olhares: a rede centrada nos grupos de poder, a centralização de cada grupo, o grau das conexões entre eles, como também incluir outros indicadores e variáveis. Entretanto, como já foi mencionado, optamos em analisá-la por uma lista pré-estabelecida, para entender “ quais são os atores centrais na rede? ”, “ quem tem o poder de intermediar os temas que envolvem o transporte coletivo de Maringá?", “ quais são os grupos mais próximos de todos os atores na rede?" e " quem tem o poder de decidir as políticas públicas para o transporte coletivo de Maringá?".

Para tanto, ao buscarmos a especificação de onde se localiza cada grupo e ator, organizamos a rede de poder em três grupos. O poder público municipal: todos os envolvidos 
com o transporte coletivo na esfera da administração pública municipal; a empresa: TCCC; e as instituições: entidades acadêmicas, sindicato, polícia militar e associações.

Como a intenção foi compreender o papel institucional do poder público, das instituições e da empresa, não inserimos nomes de secretários, diretores etc., somente o do prefeito Carlos Roberto Pupin, por ser um cargo que carrega tradições familiares e políticas, e o vereador Humberto Henrique, por ter sido o relator da CPI e um legislador que sempre questionou os assuntos sobre o transporte coletivo (quadro 1).

Quadro 1 - Maringá: Grupos/atores da rede de poder do transporte coletivo

\begin{tabular}{|c|c|}
\hline Empresa & Transporte Coletivo Cidade Canção - TCCC \\
\hline Instituições & $\begin{array}{l}\text { 40 Batalhão de Polícia Militar do Paraná - } \\
\text { (Pelotão de Trânsito); Associação Comercial e } \\
\text { Empresarial de Maringá - ACIM; Conselho de } \\
\text { Desenvolvimento de Maringá - CODEM; } \\
\text { Conselho Regional de Engenharia e Agronomia do } \\
\text { Paraná - CREA - PR; Movimento Transporte para } \\
\text { Todos; Ordem dos Advogados - OAB - Maringá; } \\
\text { Observatório das Metrópoles - Maringá; } \\
\text { Observatório Social de Maringá; Programa de } \\
\text { Pós-Graduação em Engenharia Urbana - UEM; } \\
\text { Sindicato dos Motoristas - SINTTROMAR; } \\
\text { Sindicato dos Lojistas do Comércio e do Comércio } \\
\text { Varejista de Maringá e Região - SIVAMAR }\end{array}$ \\
\hline Poder Público Municipal & $\begin{array}{l}\text { Secretaria de Trânsito e Segurança - SETRANS; } \\
\text { Secretaria de Planejamento e Urbanismo- } \\
\text { SEPLAN; Secretaria de Habitação e Interesse } \\
\text { Social - SEHABS; Secretaria de Obras Públicas - } \\
\text { SEMOP; Procuradoria Geral do Município; } \\
\text { Secretaria de Serviços Públicos - SEMUSP; } \\
\text { Secretária de Educação - SEDUC; Secretária de } \\
\text { Assistência Social e Cidadania - SASC; Câmara } \\
\text { Municipal de Maringá - CMM; PROCON; Prefeito } \\
\text { Carlos Roberto Pupin; Programa Pró-cidades do } \\
\text { Banco Interamericano de Desenvolvimento - BID; } \\
\text { Vereador Humberto Henrique (Relator da CPI dos } \\
\text { Transportes) }\end{array}$ \\
\hline
\end{tabular}

Fonte: Lei Complementar $\mathrm{N}^{\circ}$ 12.974/2013; Lei Complementar $\mathrm{n}^{\circ}$ 400/2002, CPI dos Transportes (2013) 
Org.: SOUZA, R.V.B (2016)

Cabe destacar também que, para detalhar a análise, alguns grupos foram desmembrados em subgrupos, como a Prefeitura Municipal de Maringá e a Câmara Municipal de Maringá. A primeira pela necessidade de compreender, além da Secretaria de Trânsito e Segurança (SETRANS) e da Secretaria de Planejamento e Urbanismo (SEPLAN), se outras secretarias são centrais na elaboração de políticas públicas para o transporte coletivo, embora pudéssemos inserir somente a prefeitura, compreendemos que essa opção deixaria a análise superficial. A segunda, a câmara municipal, com o presidente Francisco Gomes dos Santos (Chico Caiana) respondendo pelo poder legislativo e representando-o, e o vereador Humberto Henrique, que foi relator da CPI, além, de contrapor os assuntos relacionados ao transporte coletivo na Câmara.

Entre os 25 nomes da lista, 7 informaram não ter nenhuma relação com o transporte coletivo de Maringá, são eles: Secretaria de Habitação e Interesse Social, Secretaria de Assistência Social e Cidadania, Procuradoria Geral do Município, Observatório Social de Maringá, $4^{\circ}$ Batalhão de Política Militar do Paraná (Pelotão de Trânsito), Programa Prócidades do Banco Interamericano de Desenvolvimento - BID, PROCON e Sindicato dos Lojistas do Comércio e do Comércio Varejista e Atacadista de Maringá (SIVAMAR). Quando começamos a receber essas respostas negativas, indagamo-nos: "será que o questionário não está claro para o entrevistado? ". Como o primeiro contato foi via e-mail, decidimos realizar um segundo contato, pessoalmente, para entendermos as negativas. Entre as respostas, a que mais se destacou foi: "às vezes somos convidados a participar desses conselhos só para encher cadeira, todo mundo já sabe o resultado final” ${ }^{2}$.

Entre esses grupos, cinco deles se destacam ao informar que não tem relação com o transporte coletivo. O primeiro é a Procuradoria Geral do Município, a qual respondeu não ter relação direta com o transporte coletivo. Contudo, na mesma época, alguns casos de corrupção foram divulgados na mídia, os quais envolviam procuradores do município, em temas que também abrangiam a licitação da TCCC. Talvez esse seja um dos motivos da recusa em responder o questionário, pois, como consta no relatório da CPI, a conexão da procuradoria com a empresa de transporte coletivo é estreita, como também aparece na rede de poder.

O segundo grupo é a Secretaria de Habitação e Interesse Social (SEHABS), que é um órgão necessário para as políticas públicas de desenvolvimento urbano e de planejamento do transporte coletivo, porque ele detém as informações sobre moradia de interesse social as 
quais são fundamentais para relacionar transporte e moradia na organização do espaço urbano. Além disso, a secretaria foi mencionada duas vezes na rede de poder, sendo uma pela SETRANS e outra pelo Observatório das Metrópoles - Maringá. O terceiro grupo, o Programa Pró-Cidades do Banco Interamericano de Desenvolvimento - BID, também mencionou não ter relação com o serviço, mas tem relação direta com as políticas públicas direcionadas à estrutura urbana para o transporte coletivo, por receber recursos para obras de mobilidade urbana, como o sistema binário, as ciclovias e os corredores de ônibus para a cidade de Maringá.

O quarto grupo em destaque é o Observatório Social de Maringá, que é uma associação civil sem fins lucrativos, com o intuito de fiscalizar os recursos públicos, sejam eles municipais, estaduais ou federais. A informação que recebemos foi de que a entidade não possui elo com o transporte coletivo. Depois disso, ainda indagamos aos responsáveis, se já houve fiscalização nos contratos da prefeitura com a empresa de transporte coletivo, por parte da associação, e a resposta também foi negativa. O último grupo, a Secretaria de Assistência Social e Cidadania (SASC), é responsável por sistematizar as informações relativas às famílias carentes em Maringá, o grupo nos informou não ter relação com ninguém. Destacamos, entretanto, que ele é um importante setor quando os dados de programas permitem um diálogo com o transporte coletivo. Por meio do secretário da SETRANS, o único a citar conexão com a SASC, foi possível entender que a secretaria já tem a prática de vincular a população de baixa renda com o transporte coletivo quando solicita passagem gratuita à secretaria de transportes.

A constatação a que chegamos a partir das respostas dos 25 nomes da lista é de que a frase "relação com o transporte público" conduz, automaticamente, as pessoas a pensarem na TCCC (Grupo Constantino). Por isso, muitos omitem a resposta e até mesmo se distanciam nas relações cotidianas, com receio de eventuais consequências, porque conhecem o poder de quem determina as regras do "jogo". Isso se evidenciou pela quantidade de vezes que elaboramos o enunciado dos questionários, visto que nos primeiros contatos havia a frase “[...] quais o (a) senhor (a) indicaria como tendo alguma relação política, econômica ou de amizade, entre a entidade que representa com as demais relacionadas abaixo? ". A palavra "amizade" foi questionada por muitos entrevistados como: "não, eu não tenho relação de amizade com ninguém dessa lista" 3 e "Olha, o diretor disse que essa palavra amizade está estranha, porque aqui a única relação que nós temos é profissional" 4 . 
Para compreender como se estrutura esse poder em relação ao transporte coletivo de Maringá, optamos por analisar a rede com base na centralidade, intermediação e proximidade. Antes de iniciar a análise de cada indicador da rede, recapitulamos qual o seu objetivo, já detalhado no item anterior, e, posteriormente, examinamos os três principais nomes da lista, ou seja, aqueles que apresentam maior capacidade de exercer o poder político-econômico. Nesse viés, a centralidade é o primeiro indicador de análise, por apresentar uma rede generalizada, a qual significa o número de atores que um nó está ligado. Esse índice é dividido entre o grau de saída (OutDegree) e o grau de entrada (InDegree), em que o primeiro representa as interações do ator com a rede, o segundo, as interações da rede com o ator. Além deles, há o grau de entrada normalizado e o grau de saída normalizado, os quais correspondem aos números em percentagem. Sendo assim, para analisar a centralidade, considera-se o grau de entrada, já que ele demonstra o poder do nó em receber muitas informações e, consequentemente, com um alto nível de comunicação.

Os dados da tabela 1 apresentam como ator central a Secretária de Trânsito e Segurança (SETRANS), com 10 interações, seguido da Câmara Municipal, com 9 interações, da Associação Comercial e Empresarial de Maringá (ACIM) e o Conselho de Desenvolvimento Econômico de Maringá (CODEM), os quais somados têm 9 interações e da empresa Transporte Coletivo Cidade Canção (TCCC), com 8 interações. Esses grupos são centrais na rede do transporte coletivo, visto que são eles que concentram as informações para a elaboração de políticas públicas e que também são os procurados por outros atores quando o assunto envolve o aumento da tarifa, a construção de estruturas para ônibus, a isenção de impostos para a empresa e a elaboração de planos urbanísticos, em que o transporte coletivo está inserido. A posição central desses grupos demonstra como eles estão presentes no controle das informações que circulam na rede, transformando os assuntos do transporte coletivo concentrado e pouco participativo. Além disso, a TCCC e a ACIM/CODEM, aparecem com uma centralidade significativa, com um grau de vínculo que prevalece até mesmo o grau do prefeito Carlos Roberto Pupin, fato que evidencia que a empresa, a associação e o conselho têm a capacidade de efetivar o seu poder dentro da rede e influenciar outros atores.

Tabela 1- Maringá: Grau de centralidade da rede de poder do transporte coletivo

\begin{tabular}{ccccc} 
Ator/Nó & $\begin{array}{c}\text { Grau de } \\
\text { Saída }\end{array}$ & $\begin{array}{c}\text { Grau de } \\
\text { Entrada }\end{array}$ & $\begin{array}{c}\text { Grau de } \\
\text { Saída } \\
\text { Normalizado }\end{array}$ & $\begin{array}{c}\text { Grau de } \\
\text { Entrada } \\
\text { Normaliza } \\
\text { do }\end{array}$ \\
\hline SETRANS & 14.000 & 10.000 & 0.583 & 0.417 \\
\hline
\end{tabular}


Revista de Geografia (Recife) V. 35, No. 2, 2018

\begin{tabular}{ccccc}
\hline SEPLAN & 4.000 & 7.000 & 0.167 & 0.292 \\
\hline SEHABS & 0.000 & 2.000 & 0.000 & 0.083 \\
\hline SEMOP & 4.000 & 2.000 & 0.167 & 0.083 \\
\hline SASC & 0.000 & 1.000 & 0.000 & 0.042 \\
\hline Proc. Geral do Município & 0.000 & 5.000 & 0.000 & 0.208 \\
\hline SEMUSP & 3.000 & 1.000 & 0.125 & 0.042 \\
\hline SEDUC & 5.000 & 1.000 & 0.208 & 0.042 \\
\hline CMM & 1.000 & 9.000 & 0.042 & 0.375 \\
\hline Mov. Transporte p/ Todos & 2.000 & 1.000 & 0.083 & 0.042 \\
\hline Obs. das Metrópoles - UEM & 4.000 & 2.000 & 0.167 & 0.083 \\
\hline Obs. Social de Maringá & 0.000 & 3.000 & 0.000 & 0.125 \\
\hline PM (Pelotão de Trânsito) & 0.000 & 4.000 & 0.000 & 0.167 \\
\hline Prog. Pró - Cidades - BID & 0.000 & 1.000 & 0.000 & 0.042 \\
\hline Pref. Carlos Roberto Pupin & 5.000 & 6.000 & 0.208 & 0.250 \\
\hline Ver. Humberto Henrique & 3.000 & 2.000 & 0.125 & 0.083 \\
\hline PEU - UEM & 5.000 & 1.000 & 0.208 & 0.042 \\
\hline PROCON & 0.000 & 0.000 & 0.000 & 0.000 \\
\hline SINTTROMAR & 6.000 & 3.000 & 0.250 & 0.125 \\
\hline CREA - PR & 3.000 & 0.000 & 0.125 & 0.000 \\
\hline SIVAMAR & 0.000 & 1.000 & 0.000 & 0.042 \\
\hline OAB - Maringá & 7.000 & 0.000 & 0.292 & 0.000 \\
\hline ACIM & 4.000 & 3.000 & 0.167 & 0.125 \\
\hline CODEM & 2.000 & 6.000 & 0.083 & 0.250 \\
\hline TCCC & 7.000 & 8.000 & 0.292 & 0.333 \\
\hline & Fonte: Aplicação de Questionários $(2016)$ &
\end{tabular}

Org.: SOUZA, R.V.B (2016)

Nesse sentido, para entender como um ator/grupo é o meio para que outros nós se conectem na rede, a intermediação (Betweenness) é o indicador mais adequado. Sua análise utiliza-se dois índices, os números totais e o grau de intermediação normalizado (percentagem) sendo esse último o dado de análise. Os resultados com um alto grau de intermediação representam o poder de controlar a comunicação na rede, ou seja, a quantidade de vezes que esse nó aparece nos caminhos que ligam outros nós.

De acordo com a tabela 2, a SETRANS tem o maior grau de intermediação, com $27,3 \%$. Ela é o principal meio para que outros atores se unam na rede, sendo que as informações circulam com facilidade no órgão. Toda a estrutura político-econômica do transporte coletivo é administrada pela secretaria, onde há um setor denominado "transporte coletivo", destinado aos assuntos que envolvem o serviço, como o valor da tarifa, a fiscalização das cláusulas do contrato de concessão com a TCCC, os subsídios concedidos ao serviço e o gerenciamento do Fundo Municipal de Transportes e Segurança no Trânsito. Assim sendo, a organização da administração pública está de acordo com os interesses do grupo político que está à frente do comando do poder público local. No caso de Maringá, as principais políticas públicas para o transporte coletivo aconteceram nos mandatos da Família 
Barros e, por isso, a SETRANS é o meio pelo qual o grupo faz a intermediação com outros atores para controlar toda a comunicação da rede de poder do transporte coletivo.

O segundo grau de intermediação na rede, é o Sindicato dos Motoristas, Condutores de Veículos Rodoviários Urbanos, e Trabalhadores em Empresas de Transportes Rodoviários de Cargas e de Transporte e de Passageiros de Linhas Intermunicipal, Interestadual, de Turismo e Anexo de Maringá (SINTTROMAR), com 10,5\%. O sindicato aparece em destaque na rede, porque os motoristas também desempenham a função de cobrador. $O$ fato se agravou quando em 2013 a Câmara Municipal de Maringá proibiu o acumulo das funções e exigiu a contratação de cobradores. O prefeito Carlos Roberto Pupin, por intermédio de decreto, estabeleceu que o pagamento da passagem seria somente com o "Cartão Fácil", proibindo o uso do dinheiro (Maringá, 2014), assim, sem a necessidade de cobrador. Assim, neste contexto, ficou evidente a posição política do prefeito, pois se existia uma lei do poder legislativo solicitando a contratação de funcionários, a empresa deveria cumpria-la, mas o poder executivo reagiu para que isso não acontecesse e prevalecesse o interesse da TCCC. Por isso, o SINTTROMAR aparece na rede com alto grau de intermediação, por ter, nesse período, um acumulo de informações que envolvia o transporte coletivo.

A TCCC aparece em terceiro lugar, como a intermediadora na rede, com um grau de 9\%. O seu poder de intermediar prevalece até mesmo ao do prefeito $(7,3 \%)$, da SEPLAN (6.5\%) e da Câmara Municipal (1,9\%). As informações sobre o transporte coletivo, para alcançarem outros atores na rede, precisam transitar pela empresa. Com isso, as políticas públicas recebem interferência considerável da TCCC, porque, para um ator chegar a outro, é necessário que ela também faça a intermediação. A confirmação do poder da empresa se sobrepõe, ao observamos o grau de intermediação de grupos da sociedade civil, como o Movimento Transporte para Todos com 2\%, o Programa de Pós-Graduação em Engenharia Urbana da UEM, também com 2\% e o Observatório da Metrópoles - Maringá, com 0,8\%. A intermediação desses grupos seria primordial pela articulação junto à população que eles representam e pela quantidade de pesquisadores envolvidos com o tema do transporte coletivo. O único que aparece bem posicionado no grau de intermediação é o vereador Humberto Henrique, relator da CPI do transporte coletivo e um dos contrapontos dentro da rede de poder.

Ainda é importante apontar o papel da ACIM e do CODEM, com um grau de intermediação de $3,6 \%$ e 3,5\%, respectivamente, que, em conjunto, chegam a 7,1\%, próximos ao resultado de 7,3\%, do prefeito Carlos Roberto Pupin. A associação e o conselho 
influenciam o poder público constantemente com os planos urbanísticos/especulativos elaborados para projetar Maringá para o futuro, os quais são debatidos entre a classe empresarial, ausente da participação popular, com o objetivo de desvirtuar o Plano Diretor e o Plano de Mobilidade Urbana (exigido pela Lei $\mathrm{n}^{\circ} 12.587 / 2012$ ) e atender aos anseios do mercado imobiliário.

Tabela 2 - Maringá: Grau de intermediação da rede de poder do transporte coletivo

\begin{tabular}{ccc}
\hline Ator/Nó & Números Totais & $\begin{array}{c}\text { Intermediação } \\
\text { Normalizada }\end{array}$ \\
\hline SETRANS & 150.833 & 27.325 \\
\hline SINTTROMAR & 58.417 & 10.583 \\
\hline TCCC & 54.500 & 9.873 \\
\hline Ver. Humberto Henrique & 48.583 & 8.801 \\
\hline Perf. Carlos Roberto Pupin & 40.333 & 7.307 \\
\hline SEPLAN & 35.917 & 6.507 \\
\hline ACIM & 20.167 & 3.653 \\
\hline CODEM & 19.500 & 3.533 \\
\hline Mov. Transporte p/ Todos & 15.000 & 2.717 \\
\hline PEU - UEM & 12.417 & 2.249 \\
\hline CMM & 10.750 & 1.947 \\
\hline Obs. das Metrópoles - & 4.667 & 0.845 \\
\hline UEM & & 0.121 \\
\hline SEMUSP & 0.667 & 0.045 \\
\hline SEMOP & 0.250 & 0.000 \\
\hline Proc. Geral do Município & 0.000 & 0.000 \\
\hline SEDUC & 0.000 & 0.000 \\
\hline SEHABS & 0.000 & 0.000 \\
\hline Prog. Pró - Cidades -BID & 0.000 & 0.000 \\
\hline PROCON & 0.000 & 0.000 \\
\hline CREA - PR & 0.000 & 0.000 \\
\hline SIVAMAR & 0.000 & 0.000 \\
\hline OAB - Maringá & 0.000 & 0.000 \\
\hline SASC & 0.000 & 0.000 \\
\hline Pbs. Social de Maringá & 0.000 & 0.000 \\
\hline Pelotão de Trânsito) & 0.000 & \\
\hline
\end{tabular}

Fonte: Aplicação de Questionários (2016)

Org.: SOUZA, R.V.B (2016)

O outro indicador é o grau de proximidade (closeness), o qual possibilita averiguar o ator capaz de produzir o maior número de vínculos pela distância do seu posicionamento na rede. Para medir o índice, há o grau de entrada (incloseness) e o grau de saída (outcloseness). Utilizaremos, então, o grau de entrada, em que os números são inteiros. Quanto menor o valor mais próximo um ator está dos outros e mais independente (tabela 3). Dessa maneira, mais uma vez a SETRANS aparece em primeiro lugar com um grau de proximidade de 79, seguido 
da Câmara Municipal de Maringá com 80, da TCCC e da SEPLAN cada uma com um grau de 81 e do CODEM com um grau de proximidade de 83.

A SETRANS, além de alto grau de centralidade e de intermediação, também apresenta relevante grau de proximidade, o qual esclarece o seu vínculo com mais atores da rede de poder do transporte coletivo, pelas práticas e ações que mencionamos no grau de intermediação. Ademais, o índice de proximidade da secretaria significa uma independência na criação de políticas públicas, sendo que o órgão tem o poder de se comunicar com muitos atores e controlá-los, por ter informações que os outros atore/grupos não possuem.

A Câmara Municipal de Maringá, por sua vez, tem um alto grau de proximidade, devido a quantidade de pessoas que a compõe, no caso os quinze vereadores, responsáveis pelos interesses de grupos político-econômicos e da população. É um ambiente de confronto, consenso e caminhos das principais decisões do transporte coletivo. Com mínima diferença ao grau da câmara, encontra-se a TCCC, a qual, pelo seu poder político-econômico, pode criar uma quantidade de vínculos equivalente ao do poder legislativo, assim como o CODEM, o qual possui resultado semelhante ao da SEPLAN, ou seja, o conselho conta com um grau de proximidade na rede que forma vínculos e, consequentemente, sobrepõe os seus valores sob de outros grupos.

Tabela 3 - Maringá: Grau de proximidade da rede de poder do transporte coletivo

\begin{tabular}{ccc}
\hline Ator/Nó & Grau de Saída & Grau de Entrada \\
\hline SETRANS & 57.000 & 79.000 \\
\hline SEPLAN & 68.000 & 81.000 \\
\hline SEHABS & 168.000 & 87.000 \\
\hline SEMOP & 68.000 & 92.000 \\
\hline SASC & 168.000 & 89.000 \\
\hline Proc. Geral do Município & 168.000 & 84.000 \\
\hline SEMUSP & 74.000 & 94.000 \\
\hline SEDUC & 67.000 & 94.000 \\
\hline CMM & 77.000 & 80.000 \\
\hline Mov. Transporte p/ Todos & 76.000 & 116.000 \\
\hline Obs. das Metrópoles - UEM & 80.000 & 110.000 \\
\hline Obs. Social de Maringá & 168.000 & 84.000 \\
\hline PM (Pelotão de Trânsito) & 168.000 & 83.000 \\
\hline Prog. Pró - Cidades - BID & 168.000 & 89.000 \\
\hline Pref. Carlos Roberto Pupin & 67.000 & 84.000 \\
\hline Ver. Humberto Henrique & 62.000 & 101.000 \\
\hline PEU - UEM & 62.000 & 128.000 \\
\hline PROCON & 168.000 & 168.000 \\
\hline SINTTROMAR & 59.000 & 91.000 \\
\hline CREA - PR & 73.000 & 168.000 \\
\hline SIVAMAR & 168.000 & 97.000 \\
\hline OAB - Maringá & 56.000 & 168.000 \\
\hline ACIM & 89.000 & 87.000 \\
\hline CODEM & 79.000 & 83.000 \\
\hline
\end{tabular}




\begin{tabular}{cc}
\hline TCCC & 60.000 \\
\hline & Fonte: Aplicação de Questionários (2016) \\
Org.: SOUZA, R.V.B (2016)
\end{tabular}

Sequencialmente, alguns grupos/atores à margem da rede não foram citados nas análises, mas precisam ser explorados para compreendermos o papel que cumprem na rede, como o CREA - PR - Maringá, a OAB - Maringá, o Sindicato dos Lojistas do Comércio e do Comércio Varejista de Maringá e Região (SIVAMAR), a Política Militar (Pelotão de Trânsito) e o PROCON. À vista disso, o CREA - PR - Maringá envolve-se com o transporte coletivo, por já ter fiscalizado a acessibilidade dos ônibus municipais de Maringá (CREA PR, 2014). Contudo os seus vínculos na rede são baixos, sendo que nenhum ator afirmou ter se relacionado com a entidade. A OAB - Maringá constituiu no ano de 2016 a Comissão de Direito de Trânsito e Mobilidade Urbana, promovendo debates na entidade sobre o assunto. Também nenhum ator a mencionou, porém, a OAB - Maringá mencionou ter relação com sete atores da rede de poder. Na Polícia Militar (Pelotão de Trânsito) não identificamos nenhuma relação direta com o transporte coletivo, somente a fiscalização do trânsito, embora o nome da PM tenha sido mencionado quatro vezes, em razão da quantidade de militares que já ocuparam o cargo de secretário na SETRANS. A SIVAMAR mostra vínculo com o transporte coletivo apenas quando há necessidade de negociação sobre algum assunto acerca das passagens de ônibus dos trabalhadores do comércio. No entanto o sindicato disse que não tem relação alguma, enquanto foi citado três vezes. Já o PROCON não tem nenhuma relação com transporte coletivo e, por isso, é um nó solto na rede, ausente de ligação.

Ao gerar a rede de poder, a partir dos resultados dos questionários relativos ao transporte coletivo de Maringá, observamos os grupos/atores centrais que controlam todo o serviço e com quem se relacionam, com a representação gráfica das análises vinculadas a centralidade, a intermediação e a proximidade. Dessa forma, a rede do transporte coletivo de Maringá configura-se com base nas relações de poder político-econômico. Os grupos centrais, como SETRANS, Câmara Municipal de Maringá, ACIM/CODEM e TCCC, concentram a comunicação da rede. Por esse motivo, eles estão em posição vantajosa para interferir na elaboração de políticas públicas, seja em relação à tarifa ou às políticas estruturais, já que a possibilidade de se comunicar é maior comparada aos outros nós (figura $3)$. 
Figura 3 - Maringá: Rede de poder do transporte coletivo

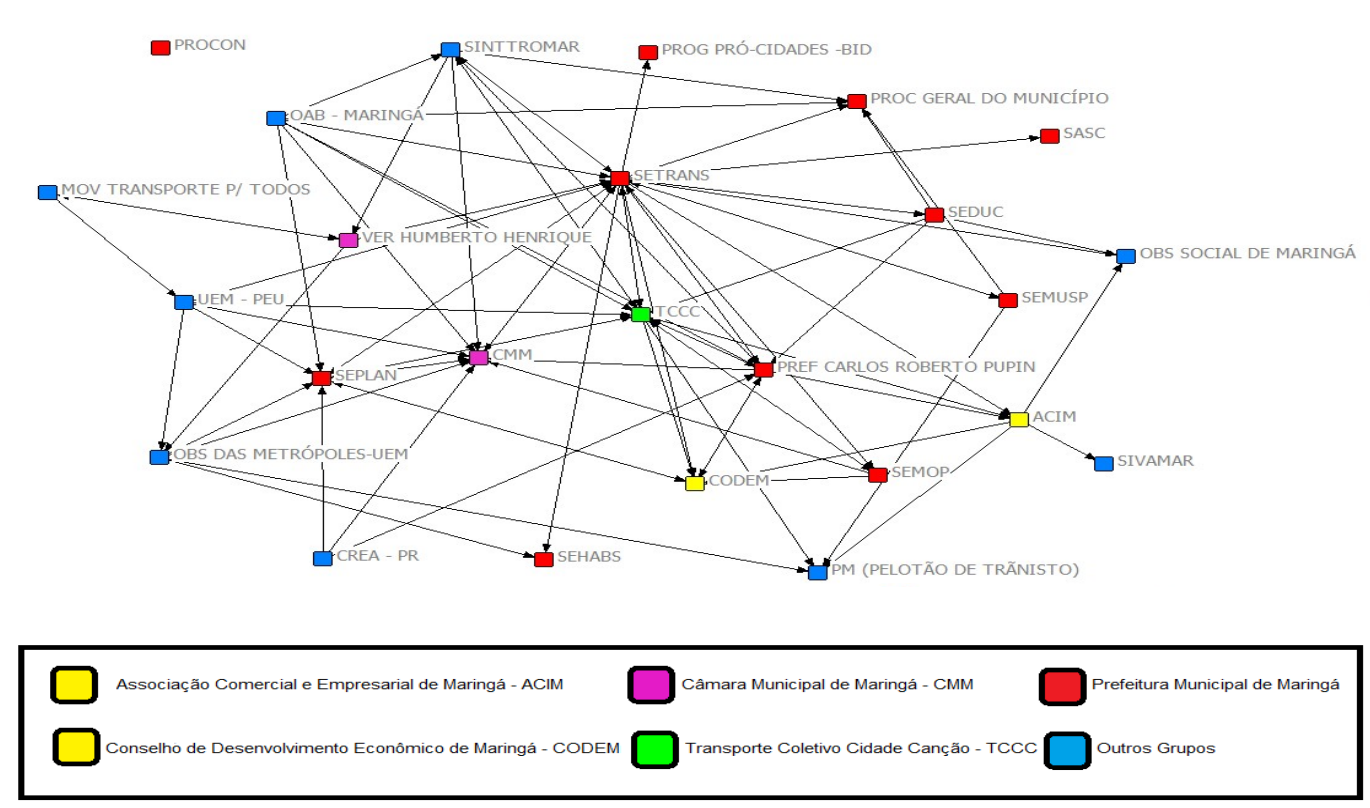

Fonte: Aplicação de Questionários (2016)

Org.: SOUZA, R.V.B (2016)

Esses grupos também são os meios para que outros atores/grupos se conectem na rede. Somente a Câmara Municipal representa um baixo índice de intermediação, enquanto os outros, com alto indicador, recebem as informações que circulam pela rede, com destaque para TCCC, que integra essa rede para preservar o seu poder em controlar o transporte coletivo. Além disso, a SETRANS, o CODEM, a TCCC, a Câmara Municipal e a SEPLAN apontam um grau de proximidade parecidos, que demonstra em que parte se concentra o poder, para definir os temas concernentes ao transporte coletivo. Em função disso, a rede de poder do transporte coletivo de Maringá demonstra como a elaboração de políticas públicas para o serviço concentra-se nas decisões de poucos atores/grupos. A rede não apresenta altos números de vínculos e, em dados momentos, não apresenta vínculos, o que elucida a ausência de participação de toda a sociedade e a omissão de alguns com o receio de se envolver com o serviço.

\section{CONSIDERAÇÕES FINAIS}

A rede de poder do transporte coletivo de Maringá demonstra que as políticas públicas para o serviço estão concentradas em alguns grupos, como a Associação Comercial Empresarial de Maringá (ACIM), conjunta ao Conselho de Desenvolvimento Econômico de Maringá (CODEM), a Transporte Coletivo Cidade Canção (TCCC), a Prefeitura Municipal de Maringá e a Câmara Municipal de Maringá. Por esse motivo é denominada como rede de 
poder, pois o poder de controlar e intermediar a elaboração de políticas públicas está concentrado na rede, ou seja, esses grupos estão em posições privilegiadas que favorecem os seus interesses particulares.

A ACIM e o CODEM, por exemplo, aparecem com grau de centralidade maior que o grau de centralidade do prefeito, isso significa que estão bem posicionados na rede para controlar os outros atores, influenciar em políticas públicas e fazer valer seus negócios. Ademais, a associação e o conselho têm o mesmo grau de intermediação que o prefeito, o que certifica que outros atores precisam das entidades para alcançar informações na rede, isso caracteriza um poder está além do econômico, ou seja, um poder político.

Já a TCCC se destaca em todos os indicadores, entretanto o grau de intermediação da empresa se sobressai, sendo o segundo da rede. Isso demostra como os outros atores/grupos dependem das informações cedidas por ela, para chegarem em outros nós da rede, o que também explica a capacidade da prestadora de serviço em se aproximar facilmente de outros atores/grupos da rede, para manter seus interesses, como o monopólio do serviço há mais de quarente anos.

A Câmara Municipal de Maringá é relevante, tanto quanto a ACIM/CODEM, no grau de centralidade. Isso significa que as ações dos dois conservam o mesmo efeito político dentro da rede. Por outro lado, a Câmara não aparece com fortes vínculos de intermediação, mas com alta capacidade de se relacionar com outros atores/grupos na rede, de tal modo que a diversidade de assuntos que tramitam todos dias entre os vereadores, faz com que eles tenham a possibilidade de se aproximar de outros indivíduos para adquirir uma informação.

A partir da elaboração da rede de poder do transporte coletivo de Maringá, é possível afirmar que a prefeitura, por meio da Secretária de Trânsito e Segurança (SETRANS), é o ponto central para elaboração, controle e influência nas políticas públicas que envolvem o serviço, visto que ela detém o poder político de gerenciar o Fundo Municipal de Transporte e Segurança, a planilha de custos do transporte coletivo, a elaboração do plano de mobilidade urbana e a comunicação com outras secretarias para a elaboração de políticas públicas. Por isso, a SETRANS, que além de ser central na rede, é também intermediária para outros grupos/atores alcançar qualquer informação.

Portanto, constatamos que as políticas públicas para o transporte coletivo em Maringá são controladas por alguns grupos para conservar interesses político-econômicos, além disso, sendo a cidade somente um recorte espacial de práticas que acontecem em outras cidades brasileiras. 


\section{NOTAS}

${ }^{1}$ Os caminhos mais curtos que um ator deve seguir para se ligar a outros nós (ALEJANDRO, NORMAN, 2005).

${ }^{2}$ Funcionário do PROCON, 2016.

${ }^{3}$ Representante da Polícia Militar, 2016

${ }^{4}$ Funcionário da TCCC, 2016

\section{REFERÊNCIAS}

ALEJADNRO, Velázquez Álvarez O.; NORMAN, Aguilar Gallegos. Manual Introdutório à Análise de Redes Sociais: Medidas de Centralidade, 2005. 36 p.

CORRÊA, Roberto Lobato. Redes Geográficas: Reflexões sobre um tema persistente. Cidades, São Paulo, v. 9, n. 16, p.199-218, dez. 2012.

DENEZ, Cleiton Costa. O Território em Disputa: Territorialidades, Redes Sociais e Grupos Políticos de Ivaiporã/PR (2000/2012),2016. 281 f. Tese (Doutorado) - PósGraduação em Geografia, Universidade Estadual de Maringá, Maringá, 2016.

IBGE - Instituto Brasileiro de Geografia e Estatística. Paraná: Maringá, infográficos: evolução populacional e pirâmide etária. 2016. Disponível em. Disponível em: < http://cidades.ibge.gov.br/painel/populacao.php?codmun=411520 >. Acesso em: 23 mai. 2016

MARQUES, Eduardo Cesar. Redes Sociais e Permeabilidade do Estado: Instituições e Atores Políticos na Produção da Infraestrutura Urbana no Rio de Janeiro. 1998. 257 f. Tese (Doutorado) - Departamento de Ciência Política do Instituto de Filosofia e Ciências Humanas, Universidade Estadual de Campinas, Campinas, 1998

MARQUES, Eduardo Cesar. Redes Sociais e Poder no Estado Brasileiro: Aprendizado a partir de políticas urbanas. Revista Brasileira de Ciências Sociais, São Paulo, v. 21, n. 60, p.15-41, fev. 2006.

MARQUES, Eduardo Cesar. Redes Sociais, Instituições e Atores Políticos no Governo da Cidade de São Paulo. São Paulo: Annablume, 2003. 251 p.

MARTELETO, Regina Maria. Análise de redes sociais: aplicação nos estudos de transferência da informação. Ciência da Informação, Brasília, v. 30, n. 1, p.71-81, jan/abr. 2001.

RAFFESTIN, Claude. Por Uma Geografia do Poder. São Paulo: Editora Ática S.A, 1993. 269 p.

SANTOS, Milton. A Natureza do Espaço. São Paulo: Edusp, 2002. 384 p.

TOMAÉL, Maria Inês; MARTELETO, Regina Maria. Redes Sociais: posições dos atores no fluxo da informação. Eletrônica de Biblioteconomia e Ciência da

Informação, Florianópolis, p.75-91, 2006. 